\title{
A EDUCAÇÃO A DIST ÂNCIA E A FORMAÇÃO DOCENTE NA UNIVERSIDADE FEDERAL DE RORAIMA: UMA ANÁLISE DA OFERTA DESSA MODALIDADE DE ENSINO
}

\author{
Sebastião Monteiro Oliveira ${ }^{45}$ \\ Antônio Cesar Barreto Lima ${ }^{46}$ \\ Shigeaki Ueki Alves da Paixão ${ }^{47}$
}

\begin{abstract}
RESUMO
Essa pesquisa faz uma rápida reflexão sobre o processo de formação docente no âmbito da Educação à Distância no Estado de Roraima, fazendo uma breve análise geral da formação no Brasil e a evolução da EaD como política de formação DOCENTE no país, em Roraima, e em particular na Universidade Federal de Roraima e UNIVIRR (Universidade Virtual de Roraima). O objetivo é mostrar e fazer uma análise da oferta da educação a distância em Boa Vista, considerando principalmente duas universidades públicas, a UFRR e instituições parceiras como a UNIVIRR e IFRR, visto que Roraima atualmente dispõe de uma rede de instituições privadas que oferecem cursos a distâncias, mas o foco desse trabalho são instituições públicas, por isso será destacada as ações da UFFR, UNIVIRR e ações evolvendo o IFRR.
\end{abstract}

Palavras - chave; Ensino a distância; formação docente; UFRR; UNIVIRR.

\section{DISTANCE EDUCATION AND TEACHING TRAINING AT THE FEDERAL UNIVERSITY OF RORAIMA: AN ANALYSIS OF THE OFFER OF THIS TEACHING MODALITY}

\begin{abstract}
This research makes a quick reflection on the process of teacher training in the context of Distance Education in the State of Roraima, making a brief general analysis of training in Brazil and the evolution of Distance Education as a teacher training policy in the country, in Roraima, and in particularly at the Federal University of Roraima and UNIVIRR (Virtual University of Roraima). The objective is to show and analyze the offer of distance education in Boa Vista, considering mainly two public universities, UFRR and partner institutions such as UNIVIRR and IFRR, since Roraima currently has a network of private institutions that offer courses at distances, but the focus of this work are public institutions, so the actions of UFFR, UNIVIRR and actions evolving the IFRR will be highlighted.
\end{abstract}

Key words; Distance learning; teacher training; UFRR; UNIVIRR.

\section{INTRODUÇÃO}

${ }^{45}$ Graduado em Pedagogia pela UFAM. Mestres em Educação pela UFAM, Doutor em Educação pela Universidade Nove de Julho (UNINOVE). Atualmente é Professor Associado I no CEDUC/UFRR, LOTADO no curso de Pedagogia e coordena o Grupo de Pesquisa Paulo Freire e Educação de Jovens e Adultos na Amazônia Setentrional.sabaufrr2018@gmail.com.

46 Graduado em Pedagogia pela Universidade Federal do Amazonas. Mestre em Ciências com área de Concentração em Educação Agrícola, Especialização em História Regional pela UFRR. Atualmente exerce a função de Pedagogo pelo IFRR. cesarpedago@bol.com.br

47 Doutorando do Programa Sociedade e Cultura da Amazônia - PPGSCA - ICHS UFAM.shigeak.turimo@hotmail.com. 
Essa pesquisa tenta apresentar um panorama geral da formação á distância na primeira década dos anos 2000, até a segunda metade da segunda década desse século, procurando fazer uma análise dos desdobramentos das ofertas de cursos á distância no Brasil e em especial no Estado de Roraima, considerando apenas instituições públicas, as instituições privadas representam uma dimensão bem maior, e atualmente, o Instituto Federal de Educação de Ciência e Tecnologia de Roraima (IFRR), apresenta ofertas substanciais de ensino a distância, mas que não faz parte do foco dessa pesquisa do período analisado, mas que aparece como parceira e como instituição ofertante nessa pesquisa.

O ensino à distância foi uma alternativa considerada de baixo custo e com uma formação aligeirada, esse processo se efetivou largamente a partir da década de 90 no Brasil e hoje podese afirmar que é uma realidade, Roraima acompanhou esse contexto e tem a UAB Universidade Aberta do Brasil, que funciona na UFRR, Universidade Federal de Roraima, e a UNIVIRR - Universidade Federal de Roraima, além disso, em 2009, com a criação da Política Nacional de formação docente - PANFOR, o IFRR - Instituto Federal de Roraima e a UERR - Universidade Estadual de Roraima, recém criada, atendem a demanda dessa política, inclusive com ofertas dos cursos de segunda licenciatura.

Portanto, a Educação à distância está amplamente consolidada no Estado Brasileiro, criando outras situações no âmbito da carreira docente, tanto no que diz respeito a formação, como o envolvimento de professores que atual no ensino superior que atuam em instituições públicas e privadas.

Em particular em Roraima, além das universidades públicas existem vário pólos de $\mathrm{EaD}$, como por exemplo a UNAMA, Clarentiano, UNOPAR, FAEL, UNIP, entre outras, coupando espaço e formando em massa.

\section{Política de formação docente à distância no Brasil}

Para entender o porquê da consolidação da Educação à Distância como política de formação, é importante uma rápida análise de seu surgimento. Ela é derivada da evolução do tradicional ensino presencial institucionalizado na sociedade moderna. Ao longo do desenvolvimento da História da Educação, assim como na História da Humanidade, foram superados muitos obstáculos, tanto no sistema produtivo quanto no sistema educacional. Historicamente, a educação está dividida em quatro períodos: no Mundo Antigo, no Mundo Medieval, no Mundo Moderno e no Mundo Contemporâneo (cf. Luzuriaga,1985). 
A Política Nacional de Formação docente só foi criado em 2009, tendo como um grande estratégia para formar professores o ensino à distância, tentando reduzir o número de professores leigos que até então atuavam sem habilitação adequada em -leno século XXI.

A consolidação do ensino da distância começa, por parte do governo federal criando a Universidade Aberta do Brasil (UAB), por meio do Decreto $\mathrm{n}^{\mathrm{o}}$ 5.800/2006, sob a responsabilidade da Diretoria de Educação a Distância, ligada à Coordenadoria de Aperfeiçoamento de Pessoal de Nível Superior (Capes), em parceria com a Secretaria de Educação a Distância do MEC. Seu objetivo é promover a formação inicial e continuada de professores, utilizando metodologias de educação a distância $(\mathrm{EaD})$. E hoje nas universidade públicas a UAB é um núcleo para oferta de cursos nessa modalidade.

A instituição do sistema UAB ocorreu logo após a promulgação do Decreto $n^{\circ}$ $5.622 / 2005$, que conferiu novo ordenamento legal à $\mathrm{EaD}$, equiparando os cursos nessa modalidade aos cursos presenciais e estabelecendo a equivalência de diplomas e certificados na educação superior.

Essa medida legal assenta--se no pressuposto de que a EaD constitui a iniciativa de maior alcance para enfrentar as novas demandas do número de egressos do ensino médio e de formação docente, estimada, em 2002, em 875 mil vagas no ensino superior (GATTI; BARRETTO, 2009).

Então, o aparecimento e o desenvolvimento da educação a distância têm início, a partir do Mundo Contemporâneo. Para Litwin (2001), inicialmente através dos cursos por correspondência até chegar aos nossos dias, incorporando o que há de mais avançado em tecnologias da inteligência (cf. Levy, 1998). Essa modalidade não é portanto, nova, funcionava como um recurso metodológico para vencer as grandes distâncias, principalmente nos antigos cursos supletivos criados no governo militar, é o caso do Projeto Minerva, que era um programa de rádio para todo Brasil, mas esta foi apenas uma das alternativas criadas, tiveram outras.

Como tendência do avanço tecnológico, o mundo atual, resultado de inúmeras transformações na cultura, na economia, no mundo do trabalho, na política, no sistema educacional, enfim, em todos os campos do conhecimento, as rápidas mudanças tem gerado uma atualização constante, ou seja, um tipo de educação contínua ao longo da vida, que com isso tenta justificar esse número tão elevado de estudantes matriculados em cursos à distância.

A formação de professores à distância ganhou uma dimensão muito grande, essa modalidade de ensino que antes era vista como um recurso, agora, em muitas situações, se tornou um fim em si mesmo, e, portanto, acaba criando um problema, porque passa a falsa ideia 
de uma formação de qualidade, mas por traz está a questão de uma formação em massa com baixo custo.

A discussão sobre a formação do professor, com a lei 9394/96, ganha novos contornos, hoje, ao ser associada à modalidade de educação à distância. É importante a análise das práticas discursivas hegemônicas de mudanças na ação pedagógica, ocorridas principalmente a partir dos anos 90 dando (re)significação da mesma em relação à formação do professor, o gerenciamento da escola e ao uso das novas tecnologias.

Neste movimento inserem-se as propostas de formação e treinamento a distância, em expansão acelerada a partir do final da década de 90, na formação de professores, algumas "práticas" consideradas como explicativas da sua consolidação, no sentido de (res)significarmos discursos sobre a formação do professor.

O curso Mídias na Educação, oferecido pelo MEC já a algum tempo, mas principalmente na primeira década dos anos 2000, foi oferecido em larga escala em todo Brasil primeiro como curso de extensão, em módulos e depois se transformava em curso de especialização, específico para professores da rede pública, esse curso reflete a preocupação do Governo Federal para capacitar professores no sentido de saber utilizar as mídias como recurso em sala de aula, embora as escolas não reflitam a preocupação porque é necessário laboratórios de informática e com profissionais que saibam atuar nessa área e com manutenção adequada. Esse curso reflete essa tendência de cursos onlines a nível de extensão, graduação e especialização, é uma realidade nas universidades públicas e privadas.

A oferta de cursos à distância cresceu muito na última década, cerca de um terço dos futuros professores no Brasil cursa graduação a distância, segundo dados do Censo do Ensino Superior 2010, divulgado no fim do ano passado (2012). Os números mostram a importância desse tipo de ensino para a qualificação de docentes: dentre 1,3 milhão de estudantes de cursos de formação de professores, mais de 400 mil estão inscritos em instituições de Educação a Distância (EAD). Dos 230 mil que concluíram uma licenciatura há dois anos, 70 mil saíram da EAD e a formação de educadores responde por $55 \%$ dos cursos on-line oferecidos no país.

Mas quando se fala em importância só se considera a questão da quantidade da oferta, é preciso fazer uma análise sobre a qualidade desses cursos, e a estrutura criada para seu funcionamento, quem trabalha com essa modalidade, e muitas outras questões, a EAD não pode ser um fim mas sim um meio para capacitar melhor os docentes.

Para os especialistas em políticas de financiamento educacional e formação docente, a oferta desse tipo de ensino influencia na qualificação dos professores no Brasil. No início do 
século XXI ainda tinha um contingente muito grande de docentes que atuavam nas escolas sem formação adequada para isso, então o governo federal usou a EAD em universidades públicas como forma de incentivar esse pessoal a se graduar", esse foi o argumento de uma coordenadora de ensino de uma famosa universidade paulista para justificar o uso dessa modalidade de ensino, e é o argumento comum nos debates sobre essa questão.

Mas por trás dessa questão está a falta de compromisso do governo, a falta de investimento, o aligeiramento da formação, os cursos à distância são mais baratos e sem vínculos de trabalho, e a maior parte da oferta pertence a iniciativa privada, e a previsão que já se fazia naquela época (início dos anos 2000), está se cumprindo no governo Bolsonaro, ou seja, os recursos para educação estão diminuindo.

\section{A formação docente à Distância na Universidade Federal de Roraima}

Roraima é uma das 27 unidades federativas do Brasil. Está situado na Região Norte do país, na Amazônia Setentrional, sendo o estado menos populoso do Brasil. Se limita com a Venezuela, Guiana, Pará e Amazonas. Ocupa uma área aproximada de 224,3 mil km. Sua capital e Boa Vista e esta totalmente no hemisfério Norte. De acordo com o Censo do IBGE em 2010, a população do Estado é de 450.479 habitantes com 15 municípios, sua população se concentra na capital, onde se localiza a UFRR. A implantação da UFRR data de 1989, quatro anos após ter sido autorizada pela Lei $\mathrm{n}^{0}$ 7.364/85, sendo a primeira Instituição Federal de Ensino Superior do estado de Roraima.

O enfrentamento dos problemas que se impõe nessa realidade apontam para a área de gestão de recursos e gestão pedagógica. Sob esses aspectos, ações específicas são delineadas para o alcance das metas, em consonância com as proposições em nível nacional como o Compromisso Todos Pela Educação, as Metas para o Milênio, criando um discurso sobre esse Plano.

Esse discurso sobre o Todos pela Educação criou uma dinâmica com uma dimensão estratégica voltada para o aluno, como que um espiral avançando progressivamente em direção ao infinito, oportunizando desenvolver todas as capacidades humanas. (Secretaria de Planejamento/RR. 2012).

Neste contexto, a educação no Estado de Roraima, nos seus mais variados níveis escolares nos mostram números consideráveis de alunos matriculados, desde a educação infantil até a educação superior. Sendo o ensino fundamental o nível que apresenta o maior 
percentual de alunos matriculados em 2010, o que representa $64,02 \%$ de todo o universo de matriculas efetivadas, que em números absolutos é de 90.481 alunos (IBGE, 2010).

É importante destacar que somente com a criação da UFRR foi possível atender a grande demanda que concluía o ensino médio e também a necessidade de formação docente, um desafio grande do recém formado Estado, criado em 1988, deixando de ser Território Federal e passando a Estado membro da Federação, tendo portanto que criar condições para formar profissionais para atuar na rede pública e particular em todos os níveis de ensino. A partir de 2000 o ensino superior se ampliou com a contribuição do antigo Centro Federal e tecnológico de Roraima, depois transformado em Instituto Federal (IFRR), e sugiram as instituições particulares de ensino superior, além da criação da Universidade Estadual de Roraima (UERR), e a Universidade Virtual de Roraima, que estimulou os cursos à distância no Estado.

Então, dentro desses aspectos, a UFRR tem o objetivo de oferecer formação para o desenvolvimento do Estado, com propostas de soluções para os desafios amazônicos, também estimulando o convívio entre as populações que vão alem do espaço fronteiriço. Para elevar a qualidade de vida da região conta com três campi: Paricarana, Cauamé e Murupu.

Dentro do programa de EAD a UFRR vincula-se ao Sistema Universidade Aberta do Brasil - UAB, criado em 2005, no âmbito do Fórum das Estatais pela Educação. Esse Sistema proporcionou através do edital de seleção UAB- 01/2006 - SEED/MEC a convocação dos Municípios, Estados e o Distrito Federal que apresentaram propostas de pólos municipais de apoio presencial, assim como, as instituições públicas de ensino superior que apresentaram propostas de cursos superiores a distância, o ingresso no Sistema UAB. Este fato possibilitou a professores do Departamento de Computação em parceria com o Departamento de Matemática da UFRR.

Não está sendo considerado aqui a participação da UFRR nos cursos oferecidos pelo MEC na Política Nacional de Formação Docente (PARFOR ${ }^{48}$ ), quem ficou responsável pela oferta destes cursos foram o IFRR, Universidade Estadual de Roraima (UERR), e também a Universidade Aberta do Brasil (UAB), que funcional na UFRR, portanto, essa análise se limita a atuação da UAB/UFRR, não se explicou os motivos que levaram a UFRR a não aderir a essa política de formação, mas é fato que não houve interesse, causando um grande prejuízo para o seu papel de maior instituição pública formadora.

\footnotetext{
${ }^{48}$ O PARFOR foi lançado no Governo Lula em 2009 com a meta de formar 330 mil professores que exerciam a profissão sem a devida formação. Era gerido pela CAPES em parceria com as secretarias de educação dos municípios e dos Estados, além de Instituições federais de ensino superior, no caso de Roraima, a UFRR não aderiu somente o IFRR.
} 
Dentro desse contexto, a UAB/UFRR, Universidade Aberta do Brasil oferece cursos de extensão, graduação: licenciatura em Matemática e licenciatura em Informática, este um curso novo que despertou o interesse de profissionais que atuam em laboratórios de informática nas escolas e cria possibilidades para os profissionais de educação buscarem conhecimento de uso do computador como recurso para favorecer a aprendizagem em sala de aula.

Além disso, também oferece cursos a nível de especialização, foi o caso do curso de especialização Mídias em Educação que formou 54 especialistas e o curso de Gestão Escolar que atendeu mais de 200 professores e gestores da rede pública do Estado, envolvendo todos os municípios.

Em 2013 foi lançado edital para iniciar as aulas no segundo semestre de 2013300 vagas para o curso de Licenciatura em Matemática à Distância pela UAB/UFRR para seis cidades do Estado: são elas: Amajarí - 50 vagas; Alto Alegre - 50 vagas; Boa Vista - 50 vagas; Bonfim 50 vagas; Caracaraí - 50 vagas e Pacaraíma - 50 vagas.

Em 2014 foi lançado edital também para o curso de Licenciatura em Informática à Distância, oferecendo 350 vagas em 07 (sete) municípios, disponibilizando 50 vagas para cada, são eles: Alto Alegre, Amajari, Boa Vista, Caracaraí, Pacaraíma, Rorainópolis e São João da Baliza.

O curso de licenciatura em Matemática é um dos cursos que mais sobra vaga no vestibular da UFRR, seria interessante uma análise demorada sobre essa questão para depois sim, fazer uma oferta racional e bem elaborada, Matemática é um dos cursos mais ofertados à distância.

Portanto, esses dois cursos estão em andamento, envolvendo uma equipe de professores, tutores, coordenadores, enfim, articulado com os pólos de informática nestes municípios com acompanhamento da UAB/UFRR.

A grande questão dessa modalidade de ensino são as críticas de seus opositores, uma forte crítica é o fato de as pessoas envolvidas não terem nenhum vínculo empregatício com a instituição, ou seja, não tem salários, nem FGTS, não tem nenhum tipo de contrato, os professores e tutores que atuam nessa modalidade são professores dos cursos da UFRR ou de fora, as poucas vagas que foram abertas para professor de carreira para atua no ensino à distância foram lotados em algum departamento ou curso, portanto, não existe um quadro permanente para essa modalidade de ensino. 
Isso implica na desvalorização da carreira, além de sobrecarregar os professores que atuam como tutores ou nos encontros presenciais em troca de uma bolsa que não compensa o desgaste físico desses profissionais.

Infelizmente isso não é um caso particular de Roraima, acontece em todo Brasil, sendo pretensão do MEC oficializar a figura do tutor como uma função na carreira do magistério, por outro lado não podemos esquecer o lado positivo dessa modalidade ensino, muitas comunidades tiveram oportunidade de ter acesso ao ensino superior, que em condições normais nunca conseguiriam frequentar um curso de graduação.

Mas isso não deve justificar o descaso do Poder Público com o ensino superior no país, especificamente na UFRR, compromete a qualidade do trabalho docente pela sobrecarga que lhes é atribuída para melhorar a renda, os professores em geral, mesmo os que atuam na Educação Básica, não trabalham os três turnos porque gostam, mas porque seus salários são irrisórios, o mesmo acontece com os professores das IFES (Instituições Federais de Ensino Superior), esses profissionais precisam de mais capacitação e valorização, tempo e recurso para atuar melhor em sala de aula e desenvolverem suas pesquisas, e terem acesso a programas de mestrado e doutorado para avançar em suas carreiras.

A década de 90 foi o marco inicial dessa modalidade de ensino, apesar de não ser um ensino tão recente, era utilizado principalmente nos cursos do antigo supletivo, no Logos para formar professores em área de carência, mas foi a partir da década de 90 que se consolidou no ensino superior como uma política de formação docente. 


\section{Considerações finais}

Os anos de 1990 e as duas primeiras décadas dos anos 2000 são muito profícuos em questão de políticas de formação docente, não necessariamente as políticas que os professores e as associações em defesa de um ensino de qualidade para todos esperavam, mas as políticas foram criadas.

A própria estrutura educacional brasileira, nesse período, iniciou o sistema de avaliação e a disponibilização de dados sobre os sistemas de ensino em todo Brasil, juntando-se a isso a postura do governo com relação ao ensino público em todos os níveis, que foi de descaso, principalmente com relação ao Ensino Médio e Superior que não cabe detalhar nesse momento, a preocupação inicial era com o ensino fundamental, e o FUNDEF foi criado privilegiando somente esse nível de ensino.

As políticas de formação docente nos anos 1990 representa a efetivação das políticas neoliberais, no que diz respeito á importância da educação enquanto instrumento impulsionador do desenvolvimento econômico do sistema capitalista, o Estado se mostrou e tem se mostrado mínimo no governo atual também e nesse momento da história brasileira (2021), está sendo dado o "tiro de misericórdia" podemos dizer assim, com tantas perdas de direitos conquistado em décadas a fio de luta.

Quando se trata do financiamento, da destinação de mais recursos para o setor educacional, tal qual a prática administrativa implementada pelo Estado Português em sua medida de "desresponsabilização" pela educação pública da colônia" (MONLEVADE, 2001, p.67). A Educvação a Distância, de certa forma, é resultado dessa preocupação, é uma política de formação mais barata e massificada.

Foi, por assim dizer, uma postura que reflete a lógica da "racionalidade financeira", recomendada por organismos internacionais de financiamento (Banco Mundial), totalmente acatada e implementada, principalmente pelo governo Fernando Henrique Cardoso, conforme evidenciado pela política educacional e de financiamento executadas durante sua gestão nos anos 90 e início dos anos 2000, seguida a risca pelo governo que o sucedeu, como bem podemos observar depois de mais de uma década do início dessas políticas. 


\section{REFERENNCIAS}

ARELARO, L. R. G. Financiamento e Qualidade da Educação Brasileira: algumas reflexões sobre o documento "Balanço do Primeiro ano do Fundef - Relatório MEC" INDOURADO, L. F. (ORG.) Financiamento da Educação Básica - Campinas, SP: Autores associados; Goiânia GO: Editora da UFG, 1999.

BRASIL. Lei no 9.394/96, de 20 de dezembro de 1996. Estabelece Diretrizes e Bases para a Educação Nacional.

GATTI, Bernardet e. Formação de Professores e Carreira . Campinas : Associados, 1997.

GATTI, B. A. Análise das políticas públicas para formação continuada no Brasil, na última década. Revista Brasileira de Educação, v. 13, p. 57-70, 2008.

GATTI, B. A. Escola: multiculturalidade e universalidade. In: SCHWARTZ, C. M. et al. (Orgs.). Desafios da educação básica: a pesquisa em educação, v. 1. Vitória: Edufes, 2007. p. 17-27.

GATTI, B. A. Formação de professores no Brasil: características e problemas. Educação e Sociedade, Campinas, v. 31, n. 113, p. 1355-1379, out./dez. 2010.

GATTI, B. A; BARRETTO, E. S. de S. Professores do Brasil: impasses e desafios. Brasília: UNESCO, 2009.

IBGE. 2010.

LITWIN, Edith (org). Educação a Distância: Temas para Debate de uma Nova Agenda Educativa. Porto Alegre, Artmed, 2001.

LUZURIAGA, Lourenzo. História da Educação e Pedagogia. 16 ed., São Paulo: Nacional, 1985. (Coleção Atualidades Pedagógicas, vol. 59).

MEC/INEP. Censo do Ensino Superior. 2010.

MONLEVADE, J. e FERREIRA, E. O FUNDEF e seus Pecados Capitais. 2 ediçãoCeilândiaDF: Idea Editora, 1998.

Idea Editora, 2001

. Educação pública no Brasil: contos e descontos. $2^{\text {a }}$ edição. Ceilândia DF:

PEREIRA, Júlio Emílio Diniz. As licenciaturas e as novas políticas educacionais para a formação docente. Revista Educação \& Sociedade, ano XX, nº 68, Dezembro/99

PINTO, J. M. R. Financiamento da Educação no Brasil: Um balanço do governo FHC (19952002). Educação e Sociedade, Setembro de 2002, Vol. 23, n ${ }^{\circ}$ 80), p. 108135. ISSN 01017330 .

PRETI, Oreste. Revista. Brasileira de. Estudos Pedagógicos., Brasìlia, v. 82, n. 200/201/202, p. 26-39, jan./dez. 2001.

PRETI, Oreste. Educação a distância: construindo significados. 2. ed. Brasília: Plano, 2000. 
Educação a distância e globalização: desafios e tendências. Revista Brasileira de Estudos Pedagógicos, Brasília, v. 79, n. 191, p. 19-30, jan./abr. 1998.

RHEINHEIMER, Adriana de Freitas. Política de Formação Contínua de Professores: A Descontinuidade das Ações e as Possíveis Contribuições. Formação de Professores / n.08. UNIVALI. S.d

SAVIANI, D. Da Nova LDB ao novo Plano Nacional de Educação: Por uma outra Política Educacional . $3^{\text {a }}$ edição rev. Campinas, SP: Autores Associados, 2000 (Coleção educação contemporânea).

Secretaria de Estado do Planejamento e Desenvolvimento de Roraima. RORAIMA: INDICADORES GERAIS - 2012. Elaboração: Fábio Rodrigues Martinez, Erlen Maria da Silva Reis, Nelcilene Farias Lima. $1^{a}$ Edição. Boa Vista: CGEES/SEPLAN - RR, 2012. 72p.

Secretaria de Estado do Planejamento e Desenvolvimento de Roraima Informações Socioeconômicas do Município de Boa Vista - RR 2012/[Elaboração: Divisão de Estudos e Pesquisas] 2a Edição. Boa Vista: CGEES/SEPLAN - RR, 2012.67p.

VIEIRA, S. L. Política Educacional em Tempos de Transição (19851995). - Brasília: Plano, 2000 .

Política Educacional no Brasil: Introdução histórica. - Brasília: Plano, 2003. WARDE, Mirian Jorge (Org). Novas Políticas Educacionais: Críticas e Perspectivas. II Seminário Internacional. Programa de Estudos Pós-Graduados em Educação.; História e Filosofia da Educação. Pontifícia Universidade Católica de São Paulo. PUC. 1998. 